\title{
On the (non-)recursivity of the prosodic word in Polish ${ }^{*}$
}

\author{
Bożena Cetnarowska \\ University of Silesia, Sosnowiec/Katowice, Poland
}

\section{The problem}

The present paper investigates the relationship between the morphological word and the prosodic word in Polish sequences consisting of proclitics and lexical words. Let us start by examining the placement of primary and secondary stresses in the phrases given in (1) in careful Polish.' Stressed syllables are marked below by capitalizing the appropriate vowels:
(1) a. pO polowAniu
b. dlA nieszczęśnIka
after hunting.loc.sg
for wretch.gen.sg
'after the hunting'
'for the/a wretched person'

In (2) the phrases from (1) are represented as sequences of feet. The digit 1 stands for the primary stress and 2 for secondary (or tertiary) stresses (as in Kraska-Szlenk 1995 or Rubach and Booij 1985). Polish words have penultimate stress, i.e. a prosodic word (henceforth PWd) has a prominent trochaic foot at the right edge. ${ }^{2}$ Following McCarthy and Prince (1993) and Selkirk (1995), I assume that feet are binary and that some unstressed syllables remain unparsed, i.e. $-l o$ - in (2a) and -szczęś- in (2b).
(2) a. $(2$
0) $0 \quad(1$
$0)$
b. $\left(\begin{array}{ll}2 & 0\end{array}\right)$
$0(10)$
po polo wa niu $(=1 \mathrm{a})$
dla nie szczęś ni ka $(=1 \mathrm{~b})$

The monosyllabic preposition and the initial syllable of the host in each phrase in (2) form a foot. McCarthy and Prince (1993:129) assert that '[b]y the Prosodic Hierarchy, no foot can

\footnotetext{
* This is a revised version of the talk given at the workshop 'Das Wort in der Phonologie' during the $22^{\text {nd }}$ meeting of the Linguistic Association of Germany (DGfS) in Marburg in March 2000. I would like to express my gratitude to the participants of the workshop for their questions and remarks, and to the editors of the present volume for their help in preparing the final version of the manuscript. I am particularly indebted to Grażyna Rowicka and Marzena Rochon for reading carefully an earlier version of the paper. I would also like to thank Geert Booij and Gienek Cyran for their comments. I am alone responsible for any remaining errors.

1 The phrases quoted here from Polish occur in their standard orthographic form. The letter ' $w$ ' is used to represent a voiced labiodental fricative (i.e. the sound transcribed as [v] in IPA transcription). The letter ' $~ '$ represents a labio-velar semivowel (i.e. [w] in IPA transcription) and ' $\mathrm{j}$ ' stands a palatal semivowel. The digraph ' $\mathrm{ch}$ ' is used for a voiceless velar fricative [ $\mathrm{x}$ ]. The digraphs ' $\mathrm{cz}$ ' and 'dż' stand for post-alveolar affricates (voiceless and voiced, respectively). Dental-alveolar affricates are represented in spelling as 'c' (voiceless) and ' $\mathrm{dz}$ ' (voiced). Post-alveolar fricatives are spelled 'sz' (voiceless) and ' $\mathrm{z}$ ' (voiced, with the variant spelling being 'rz'). Prepalatal equivalents of dental-alveolar and post-alveolar consonants are represented as sequences of such consonants and the letter ' $i$ ' (e.g. ' $i$ ', 'zi') or as the symbols ' $s$ ', ' $z$ ', ' $c$ ', 'dź' and ' $n$ '. The letter ' $y$ ' stands for a high central vowel. Nasal vowels are spelled 'a' (back) and 'ę' (front).

${ }^{2} \mathrm{~A}$ useful discussion of stress pattern in Polish can be found in Hayes (1995).
} 
straddle two PrWd's'. This assumption allows them to account for stress placement in Polish compounds, where each stem/word is a separate domain for foot-parsing (as will be shown at greater detail in section 3). Consequently, the proclitic plus host combinations in (2) cannot contain internal PWd brackets. Since the structures in (3a) and (3a') are prohibited by the Prosodic Hierarchy (and cannot be generated in GEN), I propose (3b) as the prosodic representation of $(2 a) .^{3}$
(3) a. $*\left[(2[0) 0(10)]_{\mathrm{PWd}}\right]_{\mathrm{PWd}}$
$\mathrm{a}^{\prime} \cdot *\left[(2[0) 0(10)]_{\mathrm{PWd}}\right]_{\mathrm{PPh}}$
b. $[(20) 0(10)]_{\mathrm{PWd}}$

The fact that $(3 b)$ exhibits no nested structure (i.e. it contains neither $\left[[]_{\mathrm{PWd}}\right]_{\mathrm{PPh}}$ nor $\left.\left[[]_{\mathrm{PWd}}\right]_{\mathrm{PWd}}\right)$ constitutes a violation of the constraints in (4), which align the edges of lexical (i.e. non-functional) words with the edges of prosodic words, familiar from McCarthy and Prince (1993) and Selkirk (1995):

(4) Align (Lex, $P W d$ ): 'Align the right/left edge of each lexical word with the right/left edge of some prosodic word'

By virtue of (4), we would expect a PWd edge preceding the head noun polowaniu 'hunting.loc.sg' in (1a). Moreover, if we assume that the proclitic plus host sequences in (1) and (2) do not exhibit nested prosodic structure, we come across another problem. The main (lexical) stress in Polish is placed on the penultimate syllable (Ft-Form Trochaic) and the feet headed by syllables carrying secondary stresses are constructed from left to right (as is shown in Hayes 1995 or McCarthy and Prince 1993). Rubach and Booij (1985) observe that in nonderived or non-prefixed words containing an odd number of syllables (but more than five, e.g. seven or nine), the unparsed syllable is located immediately preceding the head foot, as in (5a) and $(5 \mathrm{c})$. In procliticthost sequences consisting of an odd number of syllables (more than five), the unfooted syllable comes right after the left-most foot, as in (5b). In (5) a syllable $\sigma$ with some degree of stress is preceded by an accent mark, as in ' $\sigma$. The presence of stress is additionally marked by capitalizing the appropriate vowel. Dots indicate syllable division.

\footnotetext{
${ }^{3}$ There appears to be yet another option of bracketing (2a), given below as (i). However, such a bracketing incurs a single violation of the constraint on Foot Binarity (since it contains a degenerate one-syllable foot), a double violation of Parse $\sigma$ (by having two unparsed syllables) and a double violation of Al-L (Ft, PWd).
} 
(5) a. A.kor.dE.o.ni.stA.mi

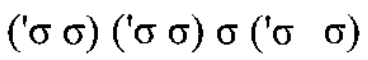

b. dlA. a.kor.dE.o.nI.stów

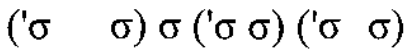

c. Or.ga.nI.za.to.rA.mi

$(' \sigma \sigma)(' \sigma \sigma) \sigma(' \sigma \sigma)$

d. dlA. or.ga.nI.za.tO.rów

$(' \sigma \quad \sigma) \sigma(' \sigma \sigma)\left({ }^{\prime} \sigma \sigma\right)$ 'accordion-player.instr.pl'

'for (the) accordion-player.gen.pl. '

'organizer.instr.pl'

'for (the) organizer.gen.pl.'

We will attempt to account for these data below.

\section{Earlier accounts of the data}

The prosodization in (3b) runs against other accounts of the clitic plus host combinations in Polish proposed in the literature. Rubach and Booij (1985) regard preposition plus lexical word combinations as phonological phrases (PPh), which corresponds roughly to the Polish term 'zestrój akcentowy' (accentual group) used in Dłuska's (1976). ${ }^{4}$ They do not divide PPhs into feet or into prosodic words, since they employ grids in their analyses. ${ }^{5}$ When analysing phrases consisting of prepositions and nouns, Rubach and Booij postulate that monosyllabic minor category words receive no lexical stress. Rules of Beat Addition (which are euphony rules in terms of Selkirk 1984) are assumed to reapply after every text-to-grid rule (e.g. Main Stress Rule and Nuclear Stress Rules) to account for the occurrence of rhythmic stresses and the avoidance of stress clashes and lapses. ${ }^{6}$ The rule of Prestress Initial, quoted in (5) after Rubach and Booij (1985), applies to phrases such as those in (1) and moves the secondary stress from the initial syllable of the head noun to the phrase initial position.

(6) $\operatorname{Prc}\left(\frac{10}{20}\right.$

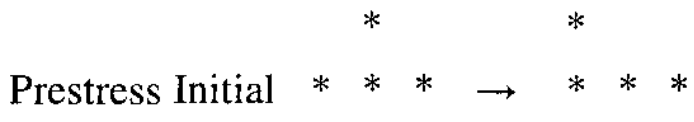

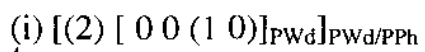

${ }^{4}$ The Phonological Phrase is defined in Rubach and Booij (1985) as consisting of one word carrying the main (i.e. lexical) stress and containing optionally monosyllabic words which normally are not members of major lexical categories.

${ }^{5}$ Nespor and Vogel (1989:115), when discussing Polish data from Rubach and Booij (1985), similarly decide that 'the alternations observed are purely rhythmic. Thus, they are most appropriately accounted for by grid operations and do not require a richer foot structure in the prosodic component.' In contrast to Rubach and Booij (1985) and McCarthy and Prince (1993), Nespor and Vogel (1986, 1989) construct flat $n$-ary branching feet, containing as many as eight syllables.

${ }^{6}$ They also employ Selkirk's (1984) Textual Prominence Preservation Condition to predict that euphony rules may not undo the prominence relations assigned by text-to-grid rules (such as the Main Stress Rule). 
Rubach and Booij's (1985) analysis is incompatible with the basic tenets of non-derivational Optimality Theory (OT) as formulated in McCarthy and Prince (1993), which allows neither for stress movement nor for cyclic rule application. In non-derivational one-level OT analysis there can be no erasure of PWd internal brackets at the end of a stratum to allow for foot formation across words (as is proposed within a derivational theory of Lexical Phonology adopted in Rubach and Booij 1990). ${ }^{7}$

Let us now summarize briefly the analysis of the clitic plus host combinations in a monograph couched within the framework of OT, namely in Kraska-Szlenk (1995). KraskaSzlenk (1995) treats the phrases in (1)-(2) as constituting Phonological Units (Punits). This corresponds roughly to the prosodic domain of the 'clitic group' postulated in Nespor and Vogel (1986). To capture the essence of Rubach and Booij's Prestress Initial, Kraska-Szlenk puts forward the constraint in (7), which aligns the left edge of a foot with the left edge of a clitic group (i.e. her 'Punit'). ${ }^{8}$

\section{(7) Align the left edge of a foot with the left edge of a Punit (clitic group)}

To predict that the presence of a monosyllabic preposition triggers a modification of the edges only of the initial foot in the noun, she takes recourse to the Identity Prominence constraint (8b). This constraint, which is a version of the Base Identity postulated in Kenstowicz (1996), evaluates the metrification for the $[\mathrm{X \# Y}]$ structure by matching it to the stress contours of the constituents $[\mathrm{X}]$ and $[\mathrm{Y}]$ occurring in isolation. It can be regarded as a subtype of OutputOutput (i.e. O-O) constraints, proposed in McCarthy and Prince (1995). The purpose of O-O constraints is to ensure phonological identity (or similarity) of morphologically related words.

\section{(8)a. Base-Identity (Kenstowicz 1996:370)}

'Given an input structure [X Y] output candidates are evaluated for how well they match $[\mathrm{X}]$ and $[\mathrm{Y}]$ if the latter occur as independent words.'

b. Identity-Prominence (Kraska-Szlenk 1995:131)

'Prominence has to be aligned with the corresponding syllables of the outputs in the identity relation.'

\footnotetext{
${ }^{7}$ An issue which remains highly controversial at the moment is whether some serial derivations should be allowed in OT, and how such a modification would affect the overall architecture of the theory. While Booij (1997) allows for both multi-level OT and O-O correspondence constraints, Rubach (2000) in his DOT (Derivational Optimality Theory) explicitly rejects all the so-called OT auxiliary theories, such as O-O correspondence theory, sympathy theory, and $\operatorname{Max}(F)$ theory. Some potentially undesirable consequences of introducing derivations and levels of constraint evaluations in OT are pointed out in McCarthy (2000:186).

${ }^{8}$ This constraint is ranked higher than her Align-Foot (=Al-L (Ft,Pwd)), which aligns the left edge of each foot with the left edge of some PWd. Constraints referring to the right edge, postulated in Kraska-Szlenk (1995), include, among others, Align (Pwd, R, Ft, R) and Align (Punit, R, Mwd, R).
} 
Base-Identity in (8a) (or Identity-Prominence in 8 b) is ranked above Parse- $\sigma$, which says that all syllables must be parsed as feet. It is violable gradiently and counts the number of instances in which the prominence of a syllable is different in the base and the related form. The joint application of the constraints in (7) and (8) produces the foot parsing in (9a). The alternative foot parsing in $\left(9 a^{\prime}\right)$ is less felicitous (and is ruled out) due to numerous violations of Base-Identity. ${ }^{9}$

(9) a. dowy. a. lie. no. wa. ne.go 'to (an) alienated (person)'
$(2 \quad 0) 0 \quad(2$
0) $0 \quad\left(\begin{array}{ll}1 & 0\end{array}\right)$
a'. $*(2$
$0)(2 \quad 0) \quad(2$
0) $\left(\begin{array}{ll}1 & 0\end{array}\right)$
b. Base:

wy. a. lie. no. wa. ne.go

'alienated.gen.sg'
$(20)(2$
0) $0 \quad(10)$

Let us point out that Kraska-Szlenk employs in her analysis the notion of Mword (Morphosyntactic word) defined as in (10) below:

(10) Morphosyntactic word (Mwd) is a final product of the morphological component of grammar. It should contain a root and an inflectional suffix (cf. Kraska-Szlenk 1995: 144).

Mwds are mainly lexical words but polysyllabic function words (e.g. prepositions, pronouns) also count as Mwds. A Mwd does not contain clitics, such as the conditional particle -by. A Punit such as po polowaniu 'after hunting' in (1a) contains one Mword, i.e. polowaniu 'hunting-loc.sg'. Kraska-Szlenk proposes constraints aligning the edges of prosodic domains (such as Foot, PWd or Punit) with the edges of Mword. It seems, thus, that Mword is a rough equivalent of Lex in McCarthy and Prince (1993) or Selkirk (1995). However, Kraska-Szlenk makes it clear that she uses Mword both as a morphosyntactic object (corresponding to Lex) and as a phonological object (corresponding to Pwd in Prince and Smolensky 1993). Moreover, she postulates the domain of a Pword (prosodic word), which is characteristically smaller than Mword (for instance, it does not include prefixes). Her Pword is relevant for external sandhi phenomena, such as syllable-allignment or devoicing. This profusion of phonological domains and ambiguity of Mword makes her analyses fairly complicated and potentially confusing.

\footnotetext{
${ }^{9}$ The prosodization of the Base given in (9b) after Kraska-Szlenk (1995) differs from my own intuitions. I would prefer to place the secondary stresses in the prefixed word wyalienowanego 'alienated, pf. gen.sg' in such a way that it resembles their distribution in the non-prefixed word alienowanego 'alienated, impf, gen.sg', where the unfooted syllable follows the syllable bearing the main stress. See footnote 15 in section 3.1. for more discussion.
} 
An even more serious objection to Kraska-Szlenk's framework is that she does not make the relationship between Punit, Mword (as a phonological object) and Pword explicit enough. When discussing prosodization of clitic plus host groups, she considers alternative foot structures of strings of syllables corresponding to Punits. It appears that in her representations the level of foot is immediately dominated by the level of Punits. ${ }^{10}$ Such an assumption would constitute a violation of one of the constraints on prosodic domination, namely Headedness (cf. Selkirk 1995). Selkirk (1995) restates the Strict Layer Hypothesis, formulated in Selkirk (1984) and Nespor and Vogel (1986), as a junction of the four constraints on prosodic domination in (11). ${ }^{11}$ She proposes that Nonrecursitivity and Exhaustivity are potentially violable, whereas Layeredness and Headedness (as stated in $11 \mathrm{c}, \mathrm{d}$ ) are not. The latter constraints are said to 'embody the essence of the Strict Layer Hypothesis' and to hold universally in all phonological representations.

\section{(11) Constraints on Prosodic Domination (Selkirk 1995)}

\section{a. Nonrecursitivity}

No $C^{\mathrm{i}}$ dominates $\mathrm{C}^{\mathrm{j}}, \mathrm{i}=\mathrm{j}$

E.g. NonRec ${ }_{P W d}$ : A prosodic word (PWd) may not dominate a PWd.

b. Exhaustivity:

No $\mathrm{C}^{\mathrm{i}}$ immediately dominates a $\mathrm{C}^{\mathrm{j}}, \mathrm{j}<\mathrm{i}-1$

E.g. $E x h_{P P h}$ : A phonological phrase (PPh) may dominate only PWd.

c. Layeredness

No $\mathrm{C}^{\mathrm{i}}$ dominates a $\mathrm{C}^{\mathrm{j}}, \mathrm{j}>\mathrm{i}$

e.g. 'No $\sigma$ dominates a Ft.'

\section{d. Headedness}

Any $C^{i}$ must dominate a $C^{i-1}$ (except if $\left.C^{i}=\sigma\right)$,

e.g. 'A PWd must dominate a Ft.'

While we reject the exact details of Kraska-Szlenk's analysis, we will adopt below a part of her theory, namely the use of the Base Identity (or Identity Prominence) constraint and the use of the notion of Mword as a morphosyntactic object.

\footnotetext{
${ }^{10}$ She says on page 141 that 'the Pword is constraint-driven and not present in the input form'. On the other hand, she observes on page 152 that domains in Polish are organized in the embedded fashion, i.e. $\mathrm{Pu}\left[\cdots \mathrm{Mw}_{\mathrm{w}}\left[\ldots \mathrm{Pw}_{\mathrm{P}}[\ldots]_{\mathrm{Pw}} \ldots\right]_{\mathrm{Mw}} \ldots .\right]_{\mathrm{Pu}}$. With reference to Mword, she suggests, moreover, that Lex=Pwd constraint from Prince and Smolensky (1993) is never violated in Polish, consequently Mword as a morphosyntactic object always corresponds to Mword as a phonological object (see section 5 of the present paper for the opposite assumption). She proposes that Mword is important for foot structure and 'prone to stress constraints' (p. 145, 157).

II The Strict Layer Hypothesis (SLH) states: 'A prosodic constituent of level C' can immediately dominate only constituents in the next level down in the prosodic hierarchy, $\mathrm{C}^{\mathrm{i}-1}$.' (cf. Selkirk 1984, Nespor and Vogel 1986).
} 


\section{Evidence from other phonological processes}

\subsection{Syllabification in Polish}

An undesirable consequence of the metrical structure proposed for preposition plus noun combinations in $(3 b)$, repeated for convenience below, is that it presents difficulty in predicting facts concerning syllabification.

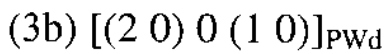

As observed in, among others, Rubach and Booij (1990:442), Polish does not permit syllabification between words or across the prefix+stem juncture. In spite of the preference for optimizing onsets, the word-final consonant in the preposition in (12a) cannot be syllabified with the following word-initial vowel of the lexical word, as shown in (12c). The word-initial vowel can be optionally preceded by a glottal stop, as in (12b). The dots in (12b, c) indicate the syllable division. ${ }^{12}$

(12) a. przed oddawaniem (orthographic form)

'before returning'

b. przed.?od.da.wa.niem

c. *prze.dod.da.wa.niem

The same phenomenon, namely a ban on trans-junctural syllabification, can be observed in the case of prefixed derivatives. ${ }^{13}$ This is illustrated in (13). The data in (14) show, in contrast, that a stem or root-final consonant can be syllabified together with the suffix-initial vowel, and that glottal stop insertion is impossible.

(13) a. nadopiekuńczy 'over-protective' (nad-'over' + opiekuńczy 'protective')

b. nad.Po.pie.kuń.czy

c.*na.do.pie.kuń.czy

(14) a. grubas

'a fat man' ( $g r u b y$ 'fat' + the nominalizing suffix -as)

b. gru.bas.

c. *grub.?as.

\footnotetext{
${ }^{12}$ Syllabification and the glottal stop insertion is also discussed in Rochon (2000), who highlights the relevance of prosodic constituents as domains of phonological processes in Polish.

${ }^{13}$ Szpyra (1989) notes that resyllabification across prefix +stem juncture is possible for some words. (I am grateful to Marzena Rochon and Grażyna Rowicka for bringing this point to my attention.) The verbs rozognić 'to heat, to inflame' and naduzyć 'to abuse', containing the prefixes roz- and nad-, can be syllabificd cither as roz.og.nić and nad.u.żýc (with a syllable edge following the prefix) or as ro.zog.nić and na.du.żyć. In my view, the first syllabification is preferred in careful speech. Szpyra (1989) regards the two syllabifications in such prefixed words as resulting from the double application of the syllabification process in the course of the derivation. The first syllabification process operates when the prefix and the verb constitute separate prosodic units. Once the prefix and the stem are reanalyzed as a single prosodic word, the resyllabification can apply once again. I will propose another tentative account of this phenomenon in section 5.
} 
McCarthy and Prince (1993:128) account for the ban on trans-junctural syllabification in Polish $^{14}$ by employing the constraint Align (Stem, L, PWd, L). They say: 'A constraint of the Align-left type requires that the left edge of each stem coincide with the left edge of a PrWd. But it also entails that the left edge of the stem not lie within a syllable or within a foot, since $\sigma$ and Ft are subordinate to PrWd in the Prosodic Hierarchy. Thus a well-aligned stem-edge is opaque to syllable-parsing and to foot-parsing.'

This analysis is not available for the data in (12) and (13) once we adopt the assumption that there are no internal PWd brackets inside strings consisting of a preposition and its host, or a prefix and a stem. Note that the prosodization of the prefixed word in (13a), represented in (15a), resembles the stress distribution in prepositon+lexical word sequences in (2), since the word-initial prefix nad-bears a secondary stress and forms a foot with the stem-initial syllable. Moreover, if the prefixed word contains an odd number of syllables (greater than five), as in (15b), the unfooted syllable will follow immediately the left-most foot. ${ }^{15}$

(15) a. nAd. o. pie. kUń.czy

$$
\text { 'over-protective' (=13a) }
$$
$(2$
0) 0
$(1$
$0)$

b. przE.or. ga.nI. zo.wA.nie 're-organizing.pf' (prze-'re-', organizowanie 'organizing, impf')
$(2$
0) 0
$(20)(1$
0)

The location of the unfooted syllable in the prefixed noun in $(15 b)$ is the same as in the preposition plus host sequences (illustrated in 5), which shows that both types of combinations call for a unified analysis.

\subsection{Yer Vocalization, Palatal Assimilation and Lexical Stress Assignment}

Another phonological process which is regarded as diagnostic of a word boundary (the socalled external sandhi effects) is yer vocalization. Yers or 'fleeting vowels' $(\varnothing)$ are vocalized as /e/ before another yer in the same phonological domain, otherwise they do not surface. ${ }^{16}$

\footnotetext{
${ }^{14}$ They discuss the data from Booij and Rubach (1990), e.g. the impossibility of resyllabification in the prefixed verb rozognic' 'to heat' and in the compound mechanizm obronny 'defense mechanism'.

${ }^{15}$ Some speakers of Polish allow for another distribution of stresses in (15b), i.e. one where the unfooted syllable surfaces immediately in front of the right-most foot. This variability in stress pattern resembles the problem of the double syllabification of prefixed words, mentioned in footnote 13. The prefixed words behave with respect to syllabification and stress placement either as non-derived words, or as preposition plus lexical word sequences.

${ }^{16}$ This is the essence of the phonological rule called Lower, as proposed in Gussmann (1980), Rubach (1984), or Szpyra (1989). Szpyra (1992a) offers a different account of the behaviour of Polish yers, in which she takes recourse to syllabic well-formedness. She claims that a yer vocalizes when the consonant that follows cannot be incorporated into any syllable. Let us further note that the raising of the vowel $/ \mathrm{o} /$ to $/ \mathrm{u} /$ is regarded by some phonologists as an indication of a PWd edge. However, it is also possible to treat it as a process occurring in closed syllables.
} 
Rubach (1984) and Szpyra (1989, 1992b) assume that prefixes and roots constitute separate phonological domains, i.e. separate phonological words. Prefixed words are then analyzed similarly to compounds, e.g. the verb oddawac 'to give back', containing the prefix $o d$ - and stem dawać, is analyzed phonologically as [[odø] [dawać]]. The verb zbratać 'to become brothers', containing the prefix $z$ - and the stem bratać, is bracketed as $[[z ø][$ bratać]]. Another analysis of such strings is outlined in Rubach and Booij (1990) and Rowicka (1999). They postulate that prefixes are usually procliticized onto the root, i.e. [odø [dawać]]. Rowicka (1999) observes, furthermore, that in order to account for the behaviour of yers in prefixed verbs containing vowelless roots in Polish, it is necessary to propose that in such cases the prefix belongs to the same phonological domain as the root, as in odebrac' 'to get back' [odø+børać] from od-and brać 'to take', or in podeschnać 'to become partly dry' from pod- and schnać 'to become dry'.

The 'troublesome' yers in prefixes attached to vowelless roots are indicated in (16) by underlining. Such yers would be predicted not to surface if a PWd bracket were postulated at the left edge of a stem:

(16) a. odesłać 'to send away, pf' (cf. odsyłać 'to send away, impf', root/søł/)

b. podeschnąc 'to become partly dry, pf' (cf. podsychać 'to become partly dry, impf', root $/ \mathrm{s} \emptyset \mathrm{x} /$ )

c. podebrać 'to filch, to pilfer, pf' (cf. podbierać 'to filch, to pilfer, impf', root /bør/)

Consequently, the data from vowel-zero alternations call for a contrast between 'synthetic affixation' (i.e. [prefix+stem]) in the case of prefixed verbs containing vowelless roots, and 'analytic affixation' (i.e. [prefix [stem]]) in the case of the remaining prefixed verbs. ${ }^{17}$

The distinction between analytic and synthetic affixation turns out to be irrelevant for predicting the placement of the main stress in a verb. For the purposes of lexical stress assignment, both types of prefixed verbs are regarded as constituting a single prosodic domain, i.e. [prefix+stem]. ${ }^{18}$ The main stress can fall on a syllable in the prefix, if it happens to be penultimate in the verb, e.g. oddać 'to return' (i.e. od-and dać), odebrać 'to take back' (i.e. ode- and brać).

To further complicate the picture, let us add that the evidence from palatal assimilation, discussed in Gussmann (1999), Rowicka (1999) and Szpyra (1989), suggests that prefixes attached both to vowelless roots and to roots containing full vowels should be analyzed as

\footnotetext{
${ }^{17}$ Although prefixes and prepositions pattern together with respect to syllabification, they behave differently with respect to yer vocalization, as is shown in Szpyra $(1989,1992 b)$. Prepositions do not belong to the same prosodic domain as hosts, therefore the preposition-final yer does not vocalize as /e/ in (ii)

(ii) a. pod schnącą bielizną 'under the laundry which is/was drying' (not: *pode schnącą bielizna)

b. nad tkanina 'above the material' (not: *nade tkanina).

${ }^{18}$ Szpyra $(1989,1992 b)$ proposes the so-called Monosyllable rule which reinterprets a sequence of two prosodic words as one prosodic word (if one of those words is monosyllabic, e.g. a prefix).
} 
belonging to a different domain than the stem/root. Rowicka (1999) shows that there is no palatalisation of the consonant $/ z /$ in front of the prefix, which suggests a nested domain [z[nieść]] for zniesśc 'to bear'. Palatal assimilation of the spirant $/ z /$ in front of the palatalized nasal or lateral is obligatory domain-internally, as in the word bli[ź]nie 'scar, dat.sg'.

Gussmann (1999) and Szpyra (1989, 1992b) show that spirants /s, z/ undergo palatal assimilation in front of coronal obstruents. Gussmann (1999) argues that such assimilation is obligatory domain-internally and domain-initially, as in [ść]ėka 'path, dim.', [źdź]bto 'blade (of grass)'. It is optional across words and across a prefix +stem juncture, as in [zø [działać]] for $z d z i a l a c$ ' to take action, to have effect' ( $z d z$-or $z d z$-). Furthermore, palatal assimilation of $/ \mathrm{s} /$ is obligatory across the prefix-stem juncture in ścinac 'to cut down, impf', ścierac 'to wipe, impf'). ${ }^{19}$ The prefix $s$ - is parsed together with the stem: ['́s +cierać] (cf. Rowicka 1999). In (17)-(19) below we illustrate clashes between the predictions of the processes discussed in this section:

A. Yer-behaviour:

(17) a. rozedrzeć 'to tear, $\mathrm{pf}$ ' (from roz- and drzeć 'to tear, $\mathrm{pf}$ ')

[rozø+dørzećc: $\quad$ synthetic affixation [pref+root]

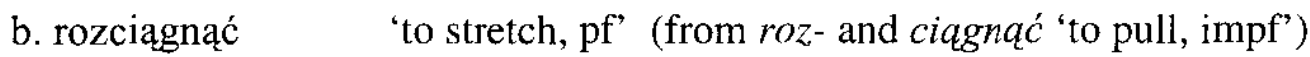

[rozø[ciągnąć]]: analytic affixation [pref[root]]

B. Palatal assimilation

(18) a. rozdzierać 'to tear, impf' (DI from rozedrzeć 'to tear, pf')

[rozø [dzierać]]: analytic affixation, optional pal.ass. ro[zdź]erać or ro[źdź]erać

b. rozciagnąć 'to stretch, pf' analytic. affixation [pref [root]], optional pal.ass. in ro[sć]agnąć or ro[ść]agnąć

c. ścinać 'to cut down, impf' synthetic affixation [prefix+root], obligatory pal.ass.in [ść]inać

C. Lexical stress assignment:

(19) a. ro.(ze.drze)

'tear.fut. $1^{\text {st }}$. sg.', synthetic prefixation [prefix+root]

$\sigma(\sigma ! !) \sigma)$

b. (roz.dać) 'to give away', synthetic prefixation [pref+root]

$(\sigma ! \sigma)$

\footnotetext{
${ }^{19}$ Szpyra (1989:218) attributes the obligatoriness of palatal assimilation in ścinać 'to cut down' to the fact that it is marked in spelling, which suggests that the process is morphologized at the word level.
} 
Since the data from processes of segmental phonology in (17)-(19) and prosodic phonology (e.g. syllabification) do not provide conclusive (and unambiguous) evidence for analyzing prefixes and stems as being in separate phonological domains, ${ }^{20}$ we will assume here that it is possible to keep the structure in (3b) (i.e. to analyze proclitic/prefix+host/stem sequences as single PWds). ${ }^{21}$ We will employ the analysis of clitics/affixes proposed for Makassarese in Basri et al. $(1998,1999)$ to predict the absence of syllabification across words or across prefix juncture. It will be briefly summarized in the next section.

\section{The analysis of Makassarese clitics}

Basri et al. (1998, 1999) postulate that languages differ in the relative ranking of Lex-PWd Alignment constraints and constraints on Prosodic Domination, quoted below after Basri et al. (1998:1).

(20) Lex-PWd Alignment Constraints

\section{a. Align $_{L}$ Lex}

Align (Lex, L, PWd, L) (=For any Lex there is a PWd such that the Left edges of Lex and PWd coincide)

\section{b. Align $n_{R}$ Lex}

Align (Lex, R, PWd, R) (=For any Lex there is a PWd such that the Right edges of Lex and PWd coincide)

\section{(21) Constraints on Prosodic Domination}

where $C^{i}$ is a prosodic category of level $i$ in the prosodic hierarchy

\section{a. Nonrecursitivity}

No $\mathrm{C}^{\mathrm{i}}$ dominates $\mathrm{C}^{\mathrm{j}}, \mathrm{i}=\mathrm{j}$

E.g. NonRec $P W d$ : A prosodic word (PWd) may not dominate a PWd.

b. Exhaustivity:

No $C^{\mathrm{i}}$ immediately dominates a $\mathrm{C}^{\mathrm{j}}, \mathrm{j}<\mathrm{i}-1$

E.g. $E_{P h_{P h}}$ : A phonological phrase (PPh) may dominate only PWd.

\footnotetext{
${ }^{20}$ It is pointed out, e.g. in Kraska-Szlenk (1995), that there is evidence for the PWd edge between a host and an enclitic, but not between a stem and a suffix. This evidence is not fully conclusive either. In strings containing the hortative plural marker - my, the placement of the main stress on the penultimate syllable, as in przeróbmy 'let's remake', indicates that it functions as a single prosodic domain, presumably PWd. On the other hand, the devoicing of the obstruent $/ \mathrm{b} /$ in front of a nasal is indicative of a word-boundary preceding the morpheme -my (word-internally we observe no obstruent devoicing in front of sonorants, cf. podobny 'similar', magma 'magma').

21 Rowicka (1999), following Polgardi (1998), assumes that phonotactic domains (i.e. domains relevant for processes of segmental phonology) are distinct from prosodic structure. Let us note that Parker (1997) proposes two disjoint metrical tiers in his OT analysis of Huariapano: one tier is relevant for segmental phonology, whereas the other tier is relevant for stress placement.
} 
Basri et al (1998:17ff) predict the following typology of languages by changing the relative ranking of the constraints given above in (20)-(21):

(22) Type A Language: Align Lex $\gg$ NonRec $_{\mathrm{PWd}}>$ Exh $_{\mathrm{PPh}}$

Type B Language: Align Lex $>\operatorname{Exh}_{\mathrm{PPh}}>>$ NonRec $_{\mathrm{PWd}}$

Type C Language: NonRec ${ }_{\mathrm{PWd}}$, Exh Exh $\mathrm{EPh}_{\mathrm{PPh}}>>$ Align Lex

Type D Language: NonRec $\mathrm{PWd}_{\mathrm{d}} \gg$ Align Lex $>\operatorname{Exh}_{\mathrm{PPh}}$

Type E Language: $\mathrm{Exh}_{\mathrm{PPh}} \gg$ Align Lex $>>$ NonRec $_{\mathrm{PWd}}$

They classify English as a Type A language and Makassarese as a Type D language. In English the constraint Align Lex dominates NonRec $\mathrm{PWd}_{\mathrm{d}}$ and $\mathrm{Exh}_{\mathrm{PPh}}$, consequently clitic plus host combinations exhibit nested structure and some material is allowed to be left unfooted in a PPh.

Let us cite at this point the typology of functional words/clitics postulated in Selkirk (1995). Selkirk (1995) posits no prosodic level of the clitic group and presents four options in the prosodization of function words, quoted here as (23). They may all be realized in one language or may be selected by various languages (option $23 \mathrm{c}$ is not selected in English, which has no internal clitics). The abbreviation finc stands for the phonological content of function words, while lex represents the phonological content of lexical (major syntactic category) words.

(23) a. ((fnc $\left.)_{\mathrm{Pwd}}(\text { lex })_{\mathrm{Pwd}}\right)_{\mathrm{PPh}}$

b. ( fnc ( lex $\left.)_{\mathrm{PWd}}\right)_{\mathrm{PPh}}$

c. ( ( fnc lex $\left.)_{\mathrm{PWd}}\right)_{\mathrm{PPh}}$

d. ( ( fnc ( lex $\left.\left.)_{\text {PWd }}\right)_{\text {PWd }}\right)_{\text {PPh }}$ function word as an independent Pword

function word as a free clitic

function word as an internal clitic

function word as an affixal clitic

The option of leaving some material unfooted in a $\mathrm{PPh}$ is realized in English in the case of free clitics, such as non-phrase final monosyllabic function words in the phrases to go or to London. Frec clitics adjoin to PWd at the level of PPh (see 23b); there is no PWd boundary at the beginning/end of such function words. Violation of NonRecPWd is exemplified by affixal clitics, which adjoin to the inner PWd and cause its recursion. Phrase-final reduced weak object pronouns in English, as in the phrases tell him or give them, are treated in Selkirk (1995) as affixal clitics.

In Makassarese, according to Basri et al. (1998, 1999), NonRec $\mathrm{PWd}_{\mathrm{P}}$ is the highest-ranked (undominated) constraint, hence there is no recursion of the PWd node. Makassarese has internal clitics, such as possessive elements - $k u$ 'my', -ta 'our', -nu 'your' and -na 'his/her/its/their'. An internal clitic is fully integrated into an adjacent content word: it is dominated by the same prosodic word node as the lexical word which serves as its host (see 
23c). The main stress in Makassarese falls upon the penultimate syllable in a PWd. The data in (24) show that the addition of possessive markers shifts the main stress rightwards, which testifies to the lack of a PWd bracket in front of them. Another piece of evidence for an absence of the internal PWd edge is the lack of stem-final mid vowel laxing in (25). The presence of the main stress is marked in (24) by capitalizing the appropriate vowel. Lax vowels in (25) are underlined.

$\begin{array}{rllll}\text { (24) a. } & \text { mejAn-na } & \text { 'his table' } & \text { mEjay } & \text { 'table' } \\ \text { b. } & \text { ballAk-ku } & \text { 'my house' } & \text { bAlla? } & \text { 'house' } \\ \text { (25) a. } & \text { birallE-ta } & \text { 'our corn' } & \text { birAlle } & \text { 'corn' } \\ \text { b. } & \text { mEjay lompO-ta } & \text { 'our big table' } & \text { lompo } & \text { 'big' }\end{array}$

Exh $_{\mathrm{PPh}}$ is ranked in Makassarese below NonRec $\mathrm{PWd}_{\mathrm{P}}$ and Align Lex, which predicts that some syllables will be left unparsed, as demonstrated for the absolutive marker - $a$ ? and the emphatic markers - $m i$,-ma in (26) (where stress assignment indicates that they are external to PWd).
(26) a. gAssin
'strong'
gAssin-a? 'I am strong'
b. bAlli
'buy'
bAlli-ma 'buy, emph'

The data from Makassarese illustrate a problem which is reminiscent of the difficulty encountered with Polish prefixes/proclitics in section 3. While some phonological phenomena (namely stress assignment and stem-final vowel laxing) indicate the lack of internal PWd edges in clitic plus host strings, there exist processes (such as the epenthesis of PWd-final V?) which call for the presence of such a PWd edge. According to Basri et al. (1998) the epenthesis in (27) (and ist absence in 28) may be interpreted as resulting from a prohibition of coda $\mathrm{r} / \mathrm{l} / \mathrm{s}$ and a requirement that a PWd end in a consonant.

(27) Stem

Bare form

Host+affixal clitic form

$\begin{array}{lllll}\text { a. /oter- } / & \text { Otere? } & \text { 'rope' } & \text { oterE?-nu } & \text { 'your rope' } \\ \text { b. /rantas-/ } & \text { rAntasa? } & \text { 'dirty' } & \text { mEjay rantasA?-na } & \text { 'his dirty table' }\end{array}$

(28) Stem

Bare form

Affixed form

/rantas/

rAntasa? 'dirty'

rantAs-an

'dirtier'

To account for the presence of the VC epenthesis in the host+clitic strings in (27), given the postulated absence of the PWd edge at the locus of epenthesis, Basri et al. $(1998,1999)$ resort to the use of O(utput)-O(utput) identity constraints (in the spirit of the theory of correspondence put forward in McCarthy and Prince 1995, Benua 1997). They regard the 
presence of the epenthetic VC sequence in the host plus affixal clitic combinations as a (phonological) 'compositionality effect'. Following the analysis for English in Selkirk (1984), Basri et al $(1998,1999)$ postulate a distinction between affixation to Stems and affixation to Words in Makassarese morphology. They also propose two families of morphological domain-sensitive $\mathrm{O}-\mathrm{O}$ faithfulness constraints: $\mathrm{O}-\mathrm{O}_{\mathrm{Word}}$. and $\mathrm{O}-\mathrm{O}_{\mathrm{Stem}}$ correspondence. The clitic plus host structures exemplified in (27) above involve affixation to Word, hence they exhibit compositionality effects, as predicted by $\mathrm{O}-\mathrm{O}_{\text {Word }}$ correspondence. The faithfulness constraint involved in this case is $\mathrm{O}-\mathrm{O}_{\mathrm{Wd}} \operatorname{Max}(\mathrm{C})$ which requires the occurrence of the same segments in two output strings. As is shown in (29), quoted from Basri et al. (1997:17), O$\mathrm{O}_{\mathrm{Wd}} \operatorname{Max}(\mathrm{C})$ outranks I-O Dep (C). The latter constraint penalizes the presence of epenthetic consonants since it predicts that each element of the output has its correspondent in the input. In contrast, the host+affix structure illustrated in (28) involves $\mathrm{O}-\mathrm{O}_{\mathrm{Stem}}$ correspondence. The constraint $\mathrm{O}-\mathrm{O}_{\mathrm{Stem}} \operatorname{Max}(\mathrm{C})$ is ranked lower than $\mathrm{O}-\mathrm{O}_{\mathrm{Wd}} \mathrm{Max}(\mathrm{C})$ and $\mathrm{I}-\mathrm{O}$ Dep $(\mathrm{C})$, hence the absence of the glottal stop:

$$
\text { Base Affiliate }
$$

\begin{tabular}{|c|c|c|c|c|c|}
\hline \multirow{3}{*}{ Output } & {$\left[[\text { rantas }]_{\text {Stem }}\right]_{\text {Word }}$} & {$\left[\left[[\text { rantas }]_{\text {Stem }}\right]_{\mathrm{Wd}}-\mathrm{nu}\right]_{\mathrm{Wd}}$} & $\begin{array}{l}\mathrm{O}-\mathrm{O}_{\mathrm{Wd}} \\
\operatorname{Max}(\mathrm{C})\end{array}$ & $\begin{array}{l}\mathrm{I}-\mathrm{O} \\
\operatorname{Dep}(\mathrm{C})\end{array}$ & $\begin{array}{l}\mathrm{O}-\mathrm{O}_{\text {Stem }} \\
\operatorname{Max}(\mathrm{C})\end{array}$ \\
\hline & \multirow[t]{2}{*}{$(\text { rAntas } \underline{a} ?)_{\mathrm{PWd}}$} & $\Rightarrow$ a. $(\operatorname{rantas} \underline{A} ? n u)_{\mathrm{PWd}}$ & & $*$ & \\
\hline & & b. $(\text { rantas Anu })_{\mathrm{PWd}}$ & $* !$ & & $*$ \\
\hline
\end{tabular}

In the next section I will attempt to employ the mechanism of O-O correspondence to account for the behaviour of strings containing prefixes or proclitics in Polish.

\section{An account of Polish proclitic plus host sequences}

It seems plausible to classify Polish as a Type C Language, in which NonRec $C_{P W d}$ and $\operatorname{Exh}_{\mathrm{PPh}}$ jointly outrank Align Lex (see 22). ${ }^{22}$ The high ranking of NonRec ${ }_{P W d}$ would predict the absence of nested structures, and would allow the proclitic/prefix and the initial syllable of a host to form a foot.

Exh $_{\mathrm{PPh}}$ is undoubtedly ranked fairly high in Polish, since there is a tendency to incorporate proclitics into their hosts, as in po oddaniu 'after returning', i.e. $(\sigma \sigma)(\sigma \sigma)$, instead of $\sigma \sigma(\sigma \sigma)$. Moreover, in a phrase such as po ich oddaniu 'lit. after their retuning (i.e. after the return of them'), a foot is formed by the two monosyllabic function words which precede their host. ${ }^{23}$

\footnotetext{
${ }^{22}$ I owe this suggestion to Lisa Selkirk.

${ }^{23}$ Peperkamp (1996) uses similar evidence to argue that $\mathrm{Exh}_{\mathrm{PPh}}$ is ranked high in Neapolitanian
} 
Although normally unstressed, one of the function words carries secondary stress in slow and deliberate speech, hence it can function as the head of a foot. ${ }^{24}$ This is illustrated in (30):

(30) a. po ich oddaniu 'lit. after their retuning' (i.e. 'after the return of them')

b. $\left.\left[\begin{array}{llll}(2 & 0\end{array}\right) \quad 0 \quad\left(\begin{array}{ll}1 & 0\end{array}\right)\right]_{\mathrm{PWd}}$

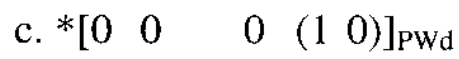

Align Lex is, thus, ranked fairly low. As a matter of fact, we need to invoke here Align Mword constraint, proposed in Kraska-Szlenk (1995), instead of Align Lex. ${ }^{25}$ Let us recall that Mwd include all Lex, i.e. all major category words, as well as polysyllabic minor category words, e.g. polysyllabic prepositions, conjunctions and pronouns.

The difference between the presence of resyllabification and palatal assimilation in stem + suffix strings and the absence of those phonological operations in prefix + stem combinations can be accounted for once we assume that prefixation in Polish involves affixation to Words, while suffixation is affixation to Stems. This assumption bears some resemblance to the proposal put forward in Rubach and Booij (1990), who regard Polish suffixes as Class 1 (cyclic) affixes and prefixes as Class 2 (postcyclic) affixes. Since prefixes are processed phonologically after suffixes, the constituency bracket '[', which indicates a left stem edge, is present at the prefix-stem juncture postcyclically, and it is able to block cyclic phonological processes. $^{26}$

Within the non-derivational model of OT adopted here the constituency brackets cannot be present in the prosodic representations of prefixed words (or proclitic plus host combinations), as was argued in section 1. However, there is a difference between morphosyntactic representations of suffixal derivatives and prefixal derivatives, as given in (31) for the words poducz 'to teach (a little), imp(erative)' and nosem 'nose, instr.sg': ${ }^{27}$

(31) a. [pod $\left.\left[[\mathrm{ucz}]_{S t e m}\right]_{W d}\right]_{W d}$

b. $\left[[\text { nos }]_{\text {Stem }} \mathrm{em}\right]_{\mathrm{Wd}}$

\footnotetext{
${ }^{24}$ The prosodization in $(30 \mathrm{c})$ is adequate for representing the stress distribution in fast speech. Rubach and Booij (1985) observe that secondary stresses in Polish disappear gradually with the increase in the tempo of speech.

${ }^{25}$ In other words, we might say that Align Lex is dominated by Align Mword which, in turn, is dominated by Exhpph and NonRec PWd $_{\text {. }}$

${ }^{26}$ Rubach and Booij (1990) do not assume that phonological and morphological operations are interspersed, which was the predominant view in earlier versions of Lexical Phonology (e.g. in Rubach 1984). They propose, instead, that all morphological derivations precede phonological ones.

${ }^{27}$ Gussmann (1980), Rubach and Booij (1990), or Szpyra (1989) assume that zero inflectional endings, such as the non.sg.masc or the imperative morpheme, should be represented as yers (since they trigger Lower). In contrast, Szpyra (1992a) argues against such an analysis, pointing out that there is no evidence for the phonetic content of such 'zero endings'. Consequently, in the structures given in (31) and the tableaux shown in (32-33) the putative zero inflectional endings are not marked.
} 
Basri et al. $(1998,1999)$ argue that affixation to Word in Makassarese involves syntactic adjunction. Some morphosyntactic evidence can be adduced in Polish to support the treatment of prefixes as syntactically adjoined to their verbal bases (hence analyzed as attaching to Words and bracketed 'outside' suffixes). Walińska (1989) proposes that Polish prefixes occupy a higher position in the VP (verb phrase) than inflectional endings. They are inserted either into the Specifier of VP or Specifier of V'. Consequently, they have influence on case assignment within VP. For instance, the accumulative prefix $n a$ - requires the direct object to be in a partitive genitive case, as in the phrase nazbierać grzybów 'to gather (a lot of) mushrooms'. In a similar vein, Slabakova (1998) analyzes all Slavic prefixes as preverbs, which are heads of upper V (i.e. they are higher than the lexical verb stems), hence they take scope over the direct object.

The representations in (31) are visible as input to correspondence constraints which evaluate the phonological affinity between the derivative and its morphological base. As in Makassarese, we can propose that the lack of faithfulness effects in Polish words containing affixes attaching to Stems result from the low ranking of $\mathrm{O}-\mathrm{O}_{\mathrm{Stem}}$ correspondence constraints. As illustrated in (32) below, O-O $\mathrm{O}_{\text {Stem }}$ Ident-Syll is outranked by ONSET, i.e. the constraint which requires that a syllable not start with a vowel.

(32) nos 'nose.nom.sg', nosem 'nose, instr.sg'

\begin{tabular}{|c|c|c|c|c|c|}
\hline \multirow[b]{2}{*}{ Input } & Base & Affiliate & & & \\
\hline & \multirow[t]{2}{*}[[\text{nos}]_{\text{Stem}}]{$_{\text {Wor d }}$} & \multirow[t]{2}{*}[[\mathrm{nos}]_{\mathrm{Stem}}\mathrm{em}]{$_{\mathrm{Wd}}$} & $\mathrm{O}-\mathrm{O}_{\mathrm{Wd}}$ & ONSET & $\mathrm{O}-\mathrm{O}_{\text {Stem }}$ \\
\hline \multirow[t]{3}{*}{ Output } & & & $\begin{array}{l}\text { Ident- } \\
\text { Syll }\end{array}$ & & $\begin{array}{l}\text { Ident- } \\
\text { Syll }\end{array}$ \\
\hline & \multirow[t]{2}{*}{$(\text { nos. })_{\mathrm{PWd}}$} & $\Rightarrow$ a. $(\text { no.sem })_{\text {PWd }}$ & & & $*$ \\
\hline & & b. $(\text { nos.em })_{\mathrm{PWd}}$ & & $* !$ & \\
\hline
\end{tabular}

The absence of trans-junctural resyllabification in the prefixed verb in (33) can be accounted for by employing O-O $\mathrm{O}_{\text {Word }}$ Ident-Syll ${ }^{28}$, which dominates ONSET and O-O $\mathrm{O}_{\text {Stem }}$ correspondence constraint. Let us emphasize once again that, although there is no PWd edge in front of the stem in poducz 'to teach (a little), imp.', phonological effects parallel to those stemming from the presence of a PWd boundary result from the application of $\mathrm{O}-\mathrm{O}_{\mathrm{Word}}$ constraints.

\footnotetext{
${ }^{28}$ The constraint in question is given the following formulation in Basri et al. (1998:11): 'The syllable structure of instances of $\mathfrak{E}$ in a word-bascd paradigm must be identical.' (Where $\mathfrak{E}$ is the base of the paradigm and $\mathcal{L}^{\prime}$ is the derivative/affiliate in the paradigm.)
} 
$\begin{array}{ll}\text { (33) } \operatorname{ucz} & \text { 'teach, imp.', } \\ \text { poducz } & \text { 'teach (a little), imp.' }\end{array}$

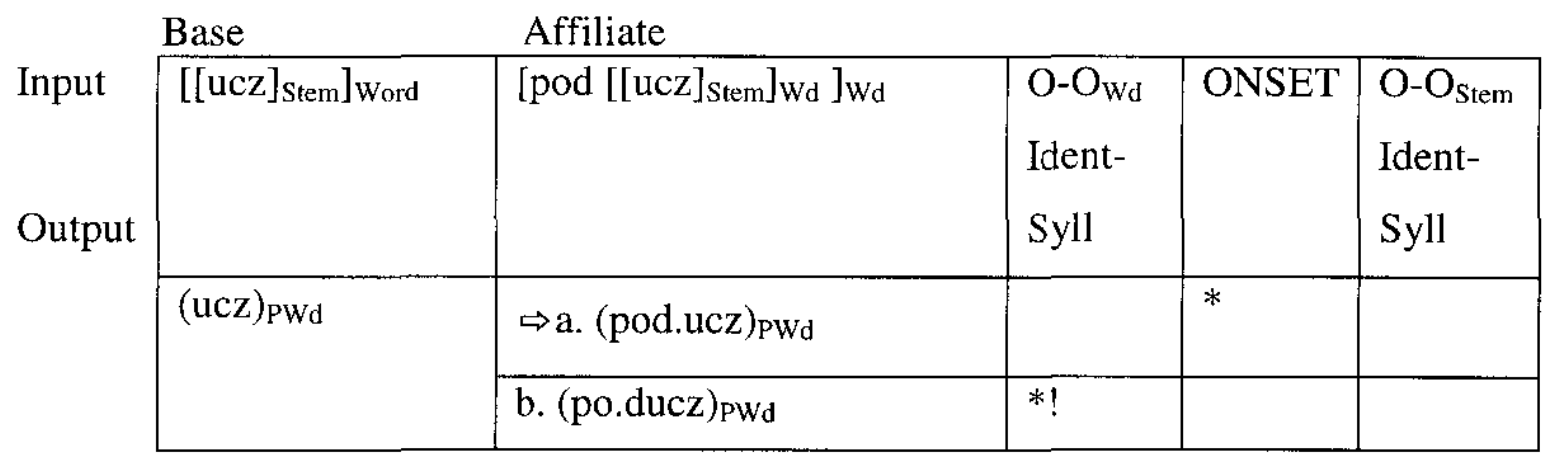

A potential problem that arises with regard to the analyses proposed here is what counts as a possible affiliate and a base. Do they need to be derivationally related? Basri et al. (1998) follow Benua (1997) and McCarthy and Prince (1995) in asserting that O-O correspondence relations hold only between strings which are dominated by morphosyntactically identical constituents appearing in the same paradigm. One of such paradigms is the word-based paradigm, defined in Basri et al (1998) as in (34):

(34) Def: 'A word-based paradigm consists of a pair of lexical category words $\{£, £ '\}$, where $£$ $=[\text { lex }]_{£}$ and $£^{\prime}=\left[[\text { lex }]_{£} £ \alpha\right] \xi^{\prime}, £$ an immediate constituent of $£^{\prime}$.

The nonembedded instance of $£$ is the base of the paradigm, $£$ is the derivative in the paradigm.'

In order to allow for output-output correspondence constraints to operate on proclitic and lexical word combinations (e.g. pod nosem 'below the/an nose') and to match them with the corresponding non-procliticized forms (e.g. nosem 'eye, instr.sg'), it is necessary to assume, following Kenstowicz (1996) and Kraska-Szlenk (1995), that there is a host-based paradigm. It includes the base (the phonological host) and the affiliate (i.e. a string consisting of the host and a clitic or clitics). ${ }^{29}$

\section{Possible extension of the analysis to host-plus-enclitic sequences}

Once we have postulated (on the basis of the data from the the proclitic plus host strings) the occurrence of O-O constraints and assumed that NonRec $\mathrm{PWd}_{\mathrm{d}}$ dominates Align Lex in Polish, it is possible to postulate that there is no PWd edge between the host and enclitic. Consequently, the phrase consisting of a proclitic followed by a host and an enclitic is one PWd. The

\footnotetext{
${ }^{29}$ A similar position seems to be taken recently in McCarthy (2000:187), where it is tentatively suggested that Output-Output correspondence relates various realizations of a word depending on its phonosyntactic context (including contextual or pausal forms of such a word).
} 
placement of the main stress on the penultimate syllable of the host (with disregard of the enclitics) can be predicted in one of two ways:

I. There can be recourse taken to O-O ${ }_{\text {Word }}$ Faith, to make sure that the placement of the primary stress in the host is the same as in the host+enclitic sequence (i.e. 'no stress shifting' effect in host+enclitic sequences in Polish would receive a similar explanation to the account of the lack of stress shift in English words containing stress-neutral (Class II) affixes proposed in Benua 1997). ${ }^{30}$

II. We can postulate a high-ranked constraint aligning the right edge of the Head Foot with the right edge of a Mword. ${ }^{31}$ This, in combination with the other constraints given in the tableau in (36), ${ }^{32}$ would predict the prosodic structure in (36a) as the winning candidate:

(35) po oddaniu ich

after returning, pf.loc. them.gen

(36) Input

po $[\text { oddaniu }]_{\text {Mwd }}$ ich

\begin{tabular}{|c|c|c|c|c|c|}
\hline & $\begin{array}{l}\text { Al-R } \\
\text { (HdFt,Mwd) }\end{array}$ & $\begin{array}{l}\text { Al-L } \\
(\mathrm{PWd}, \mathrm{Ft})\end{array}$ & Base-Id & Parse- $\sigma$ & $\begin{array}{l}\text { Al-L } \\
\text { (Ft,PWd) }\end{array}$ \\
\hline$\left.\left[\begin{array}{ll}(2 & 0\end{array}\right)\left(\begin{array}{lll}1 & 0\end{array}\right) 0\right]_{\mathrm{PWd}}$ & & & & $*$ & $2 *$ \\
\hline b. $\left[\begin{array}{lllll}0 & 0 & \left(\begin{array}{ll}1 & 0\end{array}\right) & 0\end{array}\right]_{\mathrm{PWd}}$ & & $* * !$ & & $* * *$ & $2 *$ \\
\hline c. $\left.\left[\begin{array}{lll}0 & (2 & 0\end{array}\right)(1 \quad 0)\right]_{\mathrm{PWd}}$ & $* !$ & $*$ & $* * *$ & $*$ & $4 *$ \\
\hline d. $\left.\left[\begin{array}{lll}0(1 & 0\end{array}\right)(2 \quad 0)\right]_{\text {PWd }}$ & $* !$ & $*$ & $* * *$ & $*$ & $4 *$ \\
\hline
\end{tabular}

Base: oddaniu

$0 \quad\left(\begin{array}{ll}1 & 0\end{array}\right)$

The facts from segmental phonology in the host plus enclitic combinations would, then, be accounted for by some additional O-O constraints. For instance, the lack of resyllabification

\footnotetext{
${ }^{30}$ Benua (1997) proposes that stress shifting (Class I) and stress neutral (Class II) affixes subcategorize for different Output-Output correspondence relations between the base and the affiliate (the derivative), namely $\mathrm{OO}_{1}$ and $\mathrm{OO}_{2}$-Correspondence. $\mathrm{OO}_{2}$-Faithfulness is ranked above Markedness constraints which trigger the regular stress pattern (in non-derived words). This ranking results in the preservation of base prosody in derivatives with Class II suffixes. $\mathrm{OO}_{1}$-Faithfulness, in contrast, is ranked below other stress constraints.

${ }^{31}$ This constraint, dubbed $\mathrm{Al}-\mathrm{R}(\mathrm{HdFt}, \mathrm{Mwd})$ in (36), bears superficial similarity to constraints aligning the right edge of the head foot with the right edge of some prosodic word, e.g. MainRight in Parker (1997).

32 The constraint abbreviated as Base-Id in (35) is Base Identity (given in $8 \mathrm{~b}$ ). Al-L.(Ft,PWd) is mentioned in footnotes 3 and 8 . It predicts that the left edge of each foot should coincide with the left edge of some prosodic word. The constraint $\mathrm{Al}-\mathrm{L}(\mathrm{PWd}, \mathrm{Ft})$, in turn, requires that each prosodic word aligns its left edge with the edge of some foot.
} 
or word-final devoicing observable before an enclitic could be regarded as a compositionality effect.

\section{Conclusions}

The present paper analysed the prosodization of proclitics in Polish, focusing on prepositions and prefixes. I pointed out the incompatibility of earlier analyses of proclitic plus host (or prefix plus stem) combinations with the non-derivational framework of Optimality Theory. The analyses of sequences consisting of a prefix and a stem, or a proclitic and its host, outlined in, among others, Rubach and Booij $(1985,1990)$ assume that there is a PWd edge in front of the host. Distribution of secondary (rhythmic) stresses in such strings shows, however, that the proclitic and the initial syllable of a host form a foot, which would run across a presumed PWd boundary (in violation of the Prosodic Hierarchy).

Following the analysis of Makassarese in Basri et al. (1998, 1999), I have assumed that the rankings of Lex-PWd Alignment constraints and constraints on prosodic domination (namely, Exhaustivity $_{P P h}$ and Nonrecursitivity ${ }_{P W d}$ ) are responsible for typological differences between languages. In Polish NonRec ${ }_{P W d}$ and ExhPPh outrank Align Lex, hence the combinations of proclitics and hosts, or prefixes and stems, exhibit no nested structure.

In order to account for the facts from segmental phonology, which appear to indicate the need for a strong juncture following the proclitic (or the prefix), I proposed that such (phonological) 'compositionality' effects are achieved by employing O(utput)-O(utput) constraints. They compare the phonological shape of the host and the string consisting of the host and clitic(s) attached to it.

It was tentatively suggested that such an analysis can be extended to host+enclitic combinations, which can similarly be interpreted as containing no recursion of the prosodic word node.

I emphasized two points in which the analysis offered in Basri et al. $(1998,1999)$ must be modified when applied to Polish. Firstly, instead of employing Align Lex, we need to refer to Align Mwd. Secondly, while for Basri et al. $(1998,1999)$ the relationship between the base and the affiliate is that between a (morphological) base and its derivative, in Polish (following Kraska-Szlenk 1995 and Kenstowicz 1996) we need to postulate O-O constraints that can compare the shape of the host and the clitic plus host strings. 


\section{References}

Basri, H., E. Broselow, D. Finer and E. Selkirk 1998. "Prosodic clitics in the Makassar languages". Paper read at WCCFL XVII, UBC, Vancouver, February 1998.

Basri, H., E. Broselow, D. Finer and E. Selkirk 1999. "Morphosyntax, O-O Faith and alignment: evidence from Makassarese“. Talk given at Rutgers University, April 1999.

Benua, L. 1997 [1998]. Transderivational Identity: Phonological Relations between Words. Doctoral dissertation, University of Massachusetts, Amherst.

Booij, G. 1997. "Non-derivational phonology meets Lexical Phonology". In: I. Roca (ed.) Derivations and Constraints in Phonology, 261-288. Oxford University Press, Oxford.

Dłuska, M. 1976 [1947]. Prozodia jezyka polskiego. 2nd ed. Państwowe Wydawnictwo Naukowe, Warszawa.

Gussmann, E. 1980. Studies in Abstract Phonology. MIT Press, Cambridge, Mass.

Gussmann, E. 1999. "Complexity, consonantal strength and palatal assimilation in Polish". In: W. Banyś, L. Bednarczuk and S. Karolak (eds.) Studia lingwistyczne ofiarowane Profesorowi Kazimierzowi Polańskiemu na 70-lecie Jego urodzin [A Festschrift for Kazimierz Polański on his $70^{\text {th }}$ birthday], 386-397. Wydawnictwo Uniwersytetu Śląskiego, Katowice.

Hayes, B. 1995. A Metrical Theory of Stress: Principles and Case Studies. University of Chicago Press, Chicago, Illinois.

Kenstowicz, M 1996. "Base-Identity and Uniform Exponence: Alternatives to Cyclicity". In: J. Durand and B. Laks (eds.) Current Trends in Phonology. Models and Methods, vol 1. CNSRS, ESRI: Paris X.

Kraska-Szlenk, I. 1995. The Phonology of Stress in Polish. Doctoral dissertation, University of Illinois at Urbana-Champaign.

McCarthy, J. 2000. "The prosody of phase in Rotuman". Natural Language and Linguistic Theory $18: 1,147-197$.

McCarthy, J. and A. Prince 1993. "Generalized alignment". Yearbook of Morphology 1993, 79-153.

McCarthy, J. and A. Prince 1995. "Faithfulness and Reduplicative Identity". In: J.Beckman, S.Urbanczyk and L.Walsh (eds.) University of Massachusetts Occasional Papers in Linguistics. Vol. 18: Papers in Optimality Theory, 249-384. GLSA, Amherst, Mass.

Nespor, M. and I. Vogel 1986. Prosodic Phonology. Foris Publications, Dordrecht.

Nespor, M. and I. Vogel 1989. "On clashes and lapses“. Phonology 6, 69-116.

Parker, S. 1997. "Disjoint metrical tiers and Positional Markedness in Huariapano“. Ms., University of Massachusetts, Amherst.

Peperkamp, S. 1996. "On the prosodic representation of clitics". In: U. Kleinhenz (ed.) Interfaces in Phonology, 102-127. Akademie Verlag, Berlin.

Polgardi, K. 1998. Vowel Harmony. An Account in Terms of Government and Optimality. Doctoral dissertation, HIL, Leiden. 
Prince, A. and P. Smolensky 1993. "Optimality Theory: constraint interaction in generative grammar". Ms., Rutgers University, New Brunswick and University of Colorado, Boulder.

Rochon, M. 2000. "Prosodic constituents in the representation of consonantal sequences in Polish". Paper read at $22^{\text {nd }}$ DGfS, Marburg, March 2000.

Rowicka, G. 1999. On Ghost Vowels. A Strict CV Approach. Doctoral dissertation, HIL, Leiden.

Rubach, J. 1984. Cyclic and Lexical Phonology - the Structure of Polish. Foris Publications, Dordrecht.

Rubach, J. 2000. "Glide and glottal stop insertion in Slavic languages: a DOT analysis". Linguistic Inquiry 31:2, 271-317.

Rubach, J. and G. Booij 1985. "A grid theory of stress in Polish". Lingua 66, 281-319.

Rubach, J. and G. Booij 1990. "Edge of constituent effects in Polish". Natural Language and Linguistic Theory 7, 121-158.

Selkirk, E. 1984. Phonology and Syntax: The Relation between Sound and Structure. MIT Press, Cambridge, Mass.

Selkirk, E. 1995. "The prosodic structure of function words". In: J.Beckman, S.Urbanczyk and L.Walsh (eds.) University of Massachusetts Occasional Papers in Linguistics. Vol. 18: Papers in Optimality Theory, 439-469. GLSA, Amherst, Mass.

Slabakova, R. 1998. "L2 acquisition of an aspect parameter". Journal of Slavic Linguistics 6:1, 71105.

Szpyra, J. 1989. The Phonology-Morphology Interface. Cycles, Levels and Words. Routledge, London and New York.

Szpyra, J. 1992a. "Ghost segments in non-linear phonology: Polish yers". Language 68: 277-312.

Szpyra, J. 1992b. "The phonology of Polish prefixation". In: J. Fisiak and S. Puppel (eds.) Phonological Investigations (Linguistic and Literary Studies in Eastern Europe 38). John Benjamins Publishing Company, Amsterdam/Philadelphia.

Walińska, H. 1989. "The syntax of Slavic aspect". Paper presented at the Seventh Amsterdam Colloquium, December 1989. 